\title{
ЛИПИДОПОДОБНЫЕ НАНОЧАСТИЦЫ ОКСИДА ЖЕЛЕЗА КАК ПЛАТФОРМА ДЛЯ ДОСТАВКИ НУКЛЕИНОВЫХ КИСЛОТ В ПЕЧЕНЬ
}

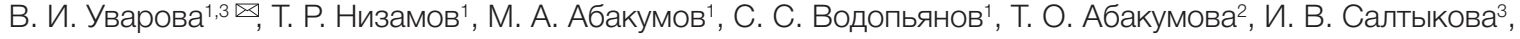 \\ П. С. Могильников ${ }^{4}$, И. В. Щетинин ${ }^{4}$, А. Г. Мажуга \\ Лаборатория биомедицинских наноматериалов, Национальный исследовательский технологический университет «МИСиС», Москва \\ 2 Центр наук о жизни, Сколковский институт науки и технологий, Москва \\ 3 Лаборатория тканеспецифических лигандов, Московский государственный университет имени М. В. Ломоносова, Москва \\ ${ }^{4}$ Кафедра физического материаловедения, Национальный исследовательский технологический университет «МИСиС», Москва \\ 5 Российский химико-технологический университет имени Д. И. Менделеева, Москва
}

\begin{abstract}
Адресная доставка антисмысловых препаратов является перспективной технологией, на основе которой возможна разработка высокоэффективных лекарственных средств для терапии широкого спектра заболеваний. Однако недостаточная стабильность РНК в биологических средах и гидрофильность, ограничивающая проникновение через клеточные мембраны, существенно сужают их использование в клинической практике. Целью исследования была разработка средств доставки антисмысловых препаратов в гепатоциты печени с помощью липидоподобных магнитных наночастиц (ЛНЧ). Кубические магнитные наночастицы (НЧ) со средними размерами 16 и 27 нм синтезировали методом высокотемпературного разложения прекурсора - олеата железа (III) и химически модифицировали формуляцией, включающей катионный липидоид С12-200. Магнитные НЧ обладают хорошими МРТ-контрастными свойствами, биораспределение ЛНЧ исследовали in vivo на линейных мышах BALB/c с помощью MP-томографа. C этой же целью провели последующее гистологическое исследование срезов печени. Наночастицы меньшего размера не продемонстрировали цитотоксического действия по отношению к клеточным линиям НерG2 и Нuh7, а для HЧ кубической формы большего размера IC ${ }_{50}$ составила 21,5 мкг/мл для НерG2 и 126 мкг/мл для Нuh7. Выявлено, что Н4 меньшего размера аккумулируются преимущественно в гепатоцитах печени, а НЧ большего размера - в селезенке, в печени же они накапливаются главным образом в макрофагах. Такая разница может быть вызвана большим гидродинамическим размером НЧ, которые имеют больший размер магнитного ядра. Образец с ядром меньшего размера является наиболее эффективной платформой для доставки антисмысловых препаратов в гепатоциты.
\end{abstract}

Ключевые слова: магнитные наночастицы, МРТ, липиды, адресная доставка

Финансирование: работа выполнена при поддержке Министерства образования и науки РФ, соглашение № 14.578 .21 .0201 (уникальный идентификатор RFMEFI57816Х0201).

$\triangle$ Для корреспонденции: Виктория Игоревна Уварова

ул. Ленинский проспект, д. 4, г. Москва, 119049; uvarova_viktoriya@bk.ru

Статья получена: 26.06.2018 Статья принята к печати: 25.08.2018

DOI: $10.24075 /$ vrgmu.2018.080

\section{LIPIDOID IRON OXIDE NANOPARTICLES ARE A PLATFORM FOR NUCLEIC ACID DELIVERY TO THE LIVER}

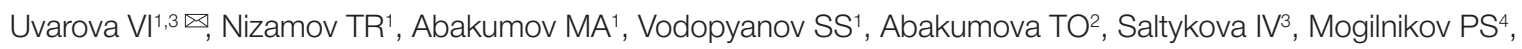
Shchetinin $I^{4}$, Majouga $A G^{1,5}$

\footnotetext{
${ }^{1}$ Laboratory of Biomedical Nanomaterials, National University of Science and Technology MISiS, Moscow

${ }^{2}$ Center of Life Science, Skolkovo Institute of Science and Technology, Moscow

${ }^{3}$ Laboratory of Tissue Specific Ligands Investigation, Lomonosov Moscow State University, Moscow

${ }^{4}$ Department of Physical Materials Science, National University of Science and Technology MISiS, Moscow

${ }^{5}$ Mendeleev University of Chemical Technology of Russia, Moscow
}

\begin{abstract}
Targeted delivery of antisense drugs is a promising technology which can provide a platform for the development of highly effective therapeuticals against a broad range of diseases. Insufficient stability of RNA in biological media coupled with hydrophilicity that prevents the molecule from penetrating cell membranes considerably limit RNA application in clinical practice. The aim of this work was to design a system for antisense drug delivery to liver hepatocytes using lipidoid magnetic nanoparticles (LNP). Nanocubes (NC) with average sizes of 16 and $27 \mathrm{~nm}$ were synthesized through decomposition of iron (III) oleate under high temperature conditions and functionalized with a cationic lipidoid C12-200. Magnetic NC demonstrated good MR-contrasting properties. Biodistribution of LNP was studied in vivo in BALB/c mice using the MR scanner. Additionally, liver sections obtained from the mice were subjected to histological examination. Nanoparticles of smaller size did not have a cytotoxic effect on HepG2 and Huh7 cell lines, whereas for larger NC, IC ${ }_{50}$ was $21.5 \mu \mathrm{g} / \mathrm{ml}$ and $126 \mu \mathrm{g} / \mathrm{ml}$ for HepG2 and Huh7 cells, respectively. Smaller particles tended to accumulate in hepatocytes. Bigger NC mainly accumulated in the spleen but also ended up in liver macrophages. This fact can be explained by a bigger hydrodynamic size of nanoparticles with a bigger magnetic core. Particles with smaller cores are a more effective platform for the delivery of antisense drugs to hepatocytes.
\end{abstract}

Keywords: magnetic nanoparticles, MRI, lipids, targeted delivery

Funding: the study was funded by the Ministry of Science and Higher Education of the Russian Federation. Project 14.578.21.0201 (ID RFMEFI57816X0201).

$\triangle$ Correspondence should be addressed: Victoria I. Uvarova

Leninsky 4, Moscow, 119049; uvarova_viktoriya@bk.ru

Received: 26.06.2018 Accepted: 25.08.2018

DOI: $10.24075 /$ brsmu.2018.080 
Известно, что повышение уровня липопротеинов низкой плотности и их метаболитов в сыворотке крови (гиперлипидемия) напрямую связано с образованием атеросклеротических бляшек и риском развития сердечно-сосудистых заболеваний [1], которые на сегодняшний день занимают первое место по смертности в мире [2]. Одним из подходов к снижению уровня липидов в крови являются методы, основанные на подавлении экспрессии целевых генов, вызывающих повышение уровня липопротеинов в плазме [3, 4]. В частности, уровни липопротеинов могут быть уменьшены с помощью ингибирования синтеза белков, играющих важную роль в их метаболизме, например ангиопоэтин-подобного белка 3 , аполипопротеинов В и С3, продуцируемых клетками печени [5]. Однако основными препятствиями на пути $\mathrm{k}$ безопасной и эффективной липидснижающей генной терапии являются проблемы, связанные с адресной доставкой антисмысловых препаратов в гепатоциты и с максимизацией выхода терапевтического агента из эндоцитарных везикул [6, 7].

Системы доставки антисмысловых препаратов традиционно разделяются на вирусные и невирусные [8, 9]. Вирусы способны с высокой эффективностью доставлять в клетки чужеродный генетический материал, однако вероятность возникновения сильного иммунного ответа (в случае аденовирусов) и риск мутагенеза (для ретровирусных векторов) вызывают активные дискуссии относительно безопасности применения подобных систем [10]. К невирусным системам переноса относятся векторы на основе неорганических НЧ [11], липосом [12, 13], комплексов с катионными липидами или полимерами [14, 15].

Среди средств доставки нуклеиновых кислот особо стоит отметить такой перспективный тип объектов, как липидоиды или липидоподобные материалы. Они показывают высокую эффективность и в роли контейнеров для доставки лекарств, и в качестве химических модификаторов поверхности НЧ для последующей загрузки нуклеиновых кислот. По результатам исследований, системы доставки PHK на основе, к примеру, липидоида C12-200 показали высокую эффективность в экспериментах на целом ряде животных, таких как грызуны и нечеловекообразные обезьяны [16]. При формировании ЛНЧ необходимы вспомогательные липиды: фузогенный фосффолипид (DSPC), увеличивающий трансфекционную активность путем дестабилизации липидного бислоя клеточных мембран, ПЭГ-липид (mPEG2000-DMG), уменьшающий иммунный ответ путем увеличения стабилизации и защиты ЛНЧ от макрофагов, и холестерин, заполняющий пространство между липидами и усиливающий активность катионных липидов [17].

Стоит отметить, что методы трансфекции сильно различаются по эфффективности, которая зависит от точности адресной доставки в орган-мишень, взаимодействия носителя с клеточной мембраной и его высвобождения из эндосом. Проблемой при использовании невирусных систем для трансфекции является то, что после эндоцитоза [18] они могут остаться изолированными в эндосомальном компартменте клеток и впоследствии привести $\mathrm{k}$ деградации терапевтического гена. Именно с этим связан активный поиск стратегий, позволяющих повысить вероятность выхода невирусных векторов из эндосом и, соответственно, эффективность трансфекции.

Одним из возможных способов обойти проблему низкой эффективности трансфекции для невирусных систем является использование структур на основе магнитных НЧ оксида железа. Наночастицы магнитных оксидов железа (магнетита, маггемита) обладают рядом привлекательных для биомедицинского применения свойств, среди которых адресная доставка лекарств, магнитная гипертермия, а также возможность использования этих НЧ в качестве контрастных агентов для магнитно-резонансной томографии (MPT) [19]. Также следует отметить, что при приложении низкочастотного магнитного поля к изучаемой системе, включающей магнитные $\mathrm{HЧ}$ и биологический объект (клетки, лабораторные животные) - благодаря эффекту броуновской релаксации, который выражается в интенсивных колебательных движениях магнитных НЧ, становится возможным контролируемое высвобождение терапевтических молекул, адсорбированных на поверхности магнитных средств доставки. Упомянутый подход способен существенно увеличить терапевтическую эффективность препаратов, так как имеются данные о более успешном в сравнении с обычными липосомами - применении магнитолипосом (т. е. липосом, содержащих магнитные НЧ) в адресной доставке лекарств (доксорубицин, паклитаксел) [20, 21].

Функциональные свойства средств доставки препаратов на основе магнитных НЧ в значительной степени определены их магнитными свойствами, например, на контрастные свойства влияет не только размер магнитных НЧ, но и их геометрия [22].

Целью исследования была разработка средств доставки нуклеиновых кислот на основе НЧ оксида железа кубической формы, функционализированных липидной формуляцией, и использование этих средств в качестве платформы для эффективной доставки антисмысловых препаратов в гепатоциты in vivo.

\section{МАТЕРИАЛЫ И МЕТОДЫ}

В работе использовали следующие материалы: 1-октадецен, триоктиламин, дибензиловый эфир, олеиновая кислота, олеат натрия, олеат железа (III), ацетат натрия безводный, холестерин, 1,2-дистеароил-sn-глицеро-3-фоссрохолин (DSPC), 1,2-димиристоил-sn-глицерополиэтиленгликоль монометиловый эфир (DMG-mPEG), N-метил-2-пирролидон (Sigma-Aldrich; США), соляная кислота, азотная кислота, этанол, бутанол-1, хлоросрорм (ООО «СигмаТек»; Россия), 1, 1'-(2-(4-(2-((2-(бис(2гидроксидодецил)амино)этил)(2-гидроксидецил)амино)этил) пиперазин-1-ил)этилазанедиил)дидодекан-2-ол (С12-200), DMEM и DMEM/F12, деионизированная вода.

\section{Клеточные культуры}

Исходный сток клеток линии Huh7 был получен из Отдела структуры и функций РНК НИИ физико-химической биологии им. А. Н. Белозерского МГУ. Исходный сток клеток культуры НерG2 был приобретен коммерческим способом через банк клеток (АТСC, НВ-8065). Работу с клетками проводили в стерильном ламинарном шкафу II класса защиты SafeFAST Elite 212 S (Faster; Италия). Клетки культивировали в $\mathrm{CO}_{2}$-инкубаторе МCO-18AIC $\mathrm{CO}_{2}$ Incubator (Sanyo; Япония) при $37^{\circ} \mathrm{C}$ и 5\% углекислого газа. Для культивирования клеточной линии Huh7 использовали среду DMEM (Corning, № 10-013-CV), содержащую 4,5 г/л глюкозы, 10\% эмбриональной бычьей сыворотки и 4 мM L-глутамина, а для клеточной линии HepG2 среду DMEM/F12 (Gibco TM , № 21331020), содержащую 10\% эмбриональной бычьей сыворотки и 4 мМ L-глутамина. 


\section{Животная модель}

Эксперименты выполняли на половозрелых самках мышей породы BALB/с возрастом 6-7 недель, весом 19-20 г, которые были приобретены в Центральном питомнике лабораторных животных Академии медицинских наук (Андреевка; Россия) и содержались в индивидуально вентилируемых клетках. Исследование одобрено этическим комитетом Российского национального исследовательскго медицинского университета им. Н. И. Пирогова (протокол № 1/2016 от 3 фревраля 2016 г.)

\section{Синтез липидоподобных наночастиц кубической формы}

Синтез прекурсора - олеата железа (III) проводили согласно стандартному протоколу [23]. НЧ магнетита кубической формы со средним размером 16 нм (CbS) получали методом термического разложения этого прекурсора в высококипящем органическом растворителе, описанным ранее [24].

Получение НЧ кубической формы со средним размером 27 нм (CbB) проводили в две стадии. На первой стадии вышеописанным методом подготавливали магнитные зародыши, на второй - путем дополнительного введения прекурсора в реакционную среду - получали Н4 большего размера. 37,5 мг зародышей, 0,35 г олеата натрия и 0,32 г олеиновой кислоты помещали в трехгорлую колбу, добавляли смесь растворителей, состоящую из 2,85 г триоктиламина и 3,13 г дибензилового эфира. Колбу, оснащенную ртутным термометром, нагревали до температуры $110^{\circ} \mathrm{C}$ при интенсивном перемешивании под током аргона, выдерживали в этих условиях 1 ч и далее нагревали смесь до температуры кипения со скоростью $5{ }^{\circ} \mathrm{C} / \mathrm{мин.} \mathrm{Затем} \mathrm{в} \mathrm{реакционную} \mathrm{среду} \mathrm{по} \mathrm{каплям} \mathrm{вносили}$ 20 мл 0,2 М раствора олеата железа (III) в дибензиловом эфире со скоростью 3 мл/ч, а далее выдерживали реакционную смесь при кипении в течение 20 мин, после чего охлаждали до комнатной температуры. Полученные НЧ отделяли с помощью магнитной декантации путем смешивания смеси с бутанолом-1. Затем осадок редиспергировали в органическом растворителе хлоросрорме и обрабатывали ультразвуком в течение 5-10 мин.

Для получения ЛНЧ использовали процедуру фазового переноса [25]. Формуляция покрытия состояла из липидоида С12-200 [26], холестерина, 1,2-дистеароилsn-глицеро-3-фосфохолина (DSPC) и 1,2-димиристоилsn-глицерополиэтиленгликоля монометилового эфира (DMG-mPEG) в массовом соотношении $75: 15: 7: 3$. Мacса формуляции липидов для покрытия - 0,9 и $1 \%$ от массы НЧ (по магнетиту) для $\mathrm{CbB}$ и $\mathrm{CbS}$ соответственно.

\section{Определение физико-химических характеристик}

\section{Просвечивающая электронная микроскопия (ПЭМ)}

Микрофотографии НЧ были получены на просвечивающем электронном микроскопе JEOL 1200-EX II TEM (JEOL; Япония) с рабочим ускоряющим напряжением 100 кВ. Образцы готовили нанесением 1-2 мкл раствора НЧ на покрытую формваром медную сетку ( $d=3,05$ мм), которую затем сушили на воздухе. Дальнейшую обработку фотограсий (расчет распределения по размерам, определение морфологии) осуществляли в версии 1.50d программы ImageJ (Wayne Rasband (NIH); CШA).

\section{Рентгенофазовый анализ (РФА)}

Рентгенофазовый анализ исследуемых образцов для определения параметров кристаллической структуры проводили на дифрактометре ДРОН-4 (ЛНПО «Буревестник»; Россия) (СоКа излучение с $\lambda=0,179$ нм, напряжение трубки $40 \mathrm{kB}$, ток 30 мА) в диапазоне дифракционных углов $2 \boldsymbol{\theta}$ от $20^{\circ}$ до $120^{\circ}$ с шагом 0,1; время экспозиции на точку съемки 3 с. Качественный фазовый анализ осуществляли путем сопоставления спектров с использованием базы данных по рентгеновским спектрам фраз (программа PHAN, около 200000 фаз).

\section{Термогравиметрический анализ и дифференциальная сканирующая калориметрия (ТГА/ДСК)}

ТГА и ДСК проводили на синхронном термоанализаторе Netzsch STA 449 F3 (NETZSCH; Германия). Нагревали образцы в алундовых тиглях в атмосфере аргона в температурном интервале от 50 до $800{ }^{\circ} \mathrm{C}$ со скоростью $10{ }^{\circ} \mathrm{C} / \mathrm{мин}$. Для проведения этих анализов растворы Н4 упаривали до состояния порошка на роторном испарителе.

\section{Вибромагнетометрия}

Измерение статических магнитных свойств в интервале магнитных полей от -20 до 20 КЭ при 300 K проводили с помощью установки Quantum Design Physical Property Measurement System (PPMS; Германия), оборудованной вибромагнетометрической вставкой (VSM), амплитуда колебаний составляла 2 мм, частота - 40 Гц. Чувствительность прибора - 10-6 э.м.е.

\section{Фотонная корреляционная спектроскопия (ФКС)}

Для определения гидродинамического размера и

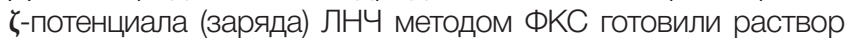
магнитных НЧ (концентрация 0,5 мг/Мл) в фоссфатносолевом буфере 1×PBS либо в дистиллированной воде. Измерение проводили с помощью прибора Zetasizer Nano ZS (Malvern; Германия) в пластиковых (или стеклянных) кюветах при $25{ }^{\circ} \mathrm{C}$. Для измерения $\zeta$-потенциала использовали капиллярные пластиковые кюветы с электродами, измерение осуществляли в дистиллированной воде.

\section{Оценка цитотоксичности липидоподобных наночастиц in vitro}

Цитотоксичность ЛНЧ оценивали с помощью MTS-теста (3-(4,5-диметилтиазол-2-ил)-5-(3-карбоксиметоксифенил)2-(4-ульфофенил)-Н-тетразолиум) [27]. Для этого клетки гепатоцеллюлярной карциномы человека Huh7 и HepG2 высаживали в 96-луночные планшеты (5000 кл./лунка) и культивировали до достижения 70\% конфлуентности монослоя (48 4, $\left.37^{\circ} \mathrm{C}, 5 \% \mathrm{CO}_{2}\right)$. Исследуемые препараты (CbS и $\mathrm{CbB}$ ) вносили в лунки в концентрации по магнетиту 370; 187; 94; 47; 23; 12; 6 мкГ/мл и 420; 210; 105; 52; 26; 13; 6 мкг/мл соответственно, после чего инкубировали в течение 24 ч ( $\left.37^{\circ} \mathrm{C}, 5 \% \mathrm{CO}_{2}\right)$, отмывали и вносили в лунки MTS-реагент. В качестве контроля клетки инкубировали в среде с добавлением эквивалентных образцам объемов фоссратно-солевого буфера (1×PBS). Оптическую 
плотность измеряли на планшетном анализаторе VictorX3 (PerkinElmer; США) при длине волны $\lambda=490$ нм. Долю выживших клеток подсчитывали как отношение оптической плотности экспериментальных образцов после внесения частиц к оптической плотности контрольных образцов. Построение грасиков и расчет значения $\mathrm{IC}_{50}$ (концентрации полуингибирования, т. е. концентрации, при которой 50\% клеток погибает) проводили с использованием программы GraphPad Prism 8.0.0 (GraphPad Software; СШA).

\section{Исследование биораспределения}

Оценку локализации ЛНЧ проводили на линейных мышах BALB/c (по три животных в группе), которым вводили Внутривенно 120 мкл раствора ЛНЧ (концентрация по железу 720 мкг/мл); животные в контрольной группе не получали инъекции.

\section{Определение динамики накопления ЛНЧ методом МРТ}

MPТ проводили с использованием 7Т MP-томографра ClinScan (Bruker Biospin; США). Для получения трансверсальных Т2взвешенных изображений применялся режим с частотным подавлением жира со следующими параметрами последовательности Turbo Spin Echo (TSE): TR/TE = 2000/42 мс, толщина среза 1 мм, матрица 380 • 640, $\mathrm{FOV}=34 \cdot 60$ мм. Для оценки накопления НЧ в динамике МРТ-исследования проводили до введения частиц, через 1 ч, 12 ч, 24 ч и 48 ч после инъекции.

\section{Гистологические исследования}

Через 48 ч после внутривенной инъекции ЛНЧ животным вводили интраперитонеально летальную дозу золетила. После исчезновения рефлексов срединным надрезом вскрывали брюшную полость, грудину рассекали с двух сторон поперек ребер. После этого полость правого предсердия вскрывали, а иглу, введенную в левый желудочек, через канюлю присоединяли к шприцу Жане. Перфузию проводили 40 мл фосфатно-солевого буфера. Затем производили дислокацию шейных позвонков и извлекали органы: печень, селезенку, почки, сердце, легкие. Извлеченные органы фиксировали 4\%-м раствором параформальдегида и хранили при $4{ }^{\circ} \mathrm{C}$ до проведения дальнейших исследований. На вибратоме Thermo Scientific Microm HM 650 V Vibration (Thermo Fisher Scientific; США) получали срезы толщиной 60 мкм. Затем их окрашивали по Перлсу набором красителей

A

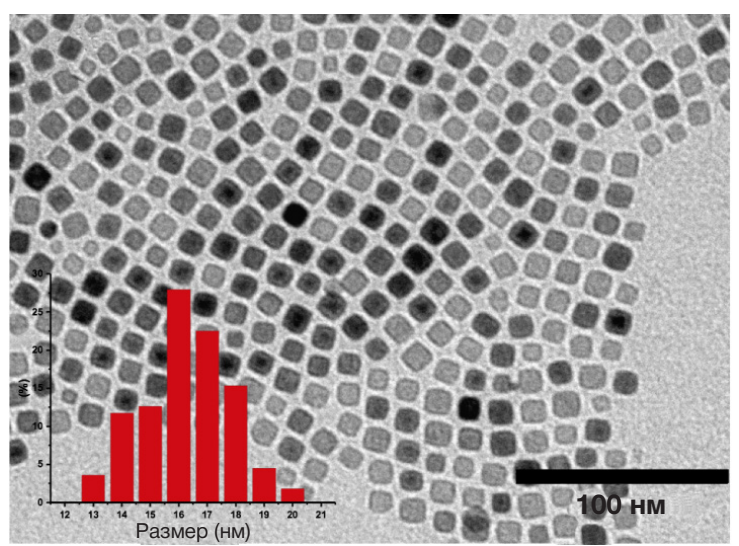

Iron Stain Kit (Sigma-Aldrich; США). При реакции Перлса гистологические срезы обрабатывали смесью растворов соляной кислоты и гексацианоферрата (II) калия; депозиты соединений железа в тканях под действием этих растворов образуют берлинскую лазурь, гранулы которой (цвета разных оттенков синего) обнаруживаются при световой микроскопии. После двукратной отмывки дистиллированной водой срезы заключали в 70\%-й глицерин. Микрофотографии готовых гистологических срезов делали при помощи светового микроскопа Carl Zeiss (Германия), оснащенного камерой Axioplan 2 Imaging.

Определение биораспределения железа во внутренних органах методом атомно-эмиссионной спектрометрии с индуктивно-связанной плазмой (АЭС)

Фрагменты (примерно треть печени и селезенки, одна почка, одно легкое, половина сердца) фиксированных органов растворяли в 2 мл свежеприготовленного раствора смеси 1500 мкл концентрированной соляной $(\mathrm{HCl})$ и 500 мкл азотной $\left(\mathrm{HNO}_{3}\right)$ кислот. Инкубировали фрагменты в растворе кислот в течение 24 ч, после чего доводили водой до конечного объема в 20 мл для печени и селезенки и 10 мл для сердца, почки и легкого; разбавленные растворы использовали для анализа концентрации железа. После построения калибровочной кривой выполняли измерение концентрации железа на атомно-эмиссионном спектрометре 4200 MP-AES (Agilent Technologies, CШA).

\section{РЕЗУЛЬТАТЫ ИССЛЕДОВАНИЯ}

Микроффотография монодисперсных кубических НЧ со средним размером 16 нм (CbS), полученная с помощью ПЭМ, и гистограммы распределения по размеру представлены на рис. 1А. Более крупные кубические НЧ (CbB) размером 20-30 нм на ПЭМ-изображении имеют четко определенную морфологию, ограненную кубическую форму (рис. 1Б).

Результаты рентгенофазового анализа обоих образцов очень похожи: положения пиков на дифракционной картине соответствуют структуре обращенной шпинели для магнетита с параметрами решетки, равными 0,838 нм и 0,839 нм для образцов CbS и CbB соответственно (рис. 2A). Петли магнитного гистерезиса (рис. 2Б) свидетельствуют о том, что образцы CbS и CbB являются ферримагнетиками с коэрцитивной силой 20-30 kA/м; для образца $\mathrm{CbS}$ намагниченность насыщения (Ms) составляет $61 \mathrm{~A} \cdot \mathrm{M}^{2} / \mathrm{K}$.

Б

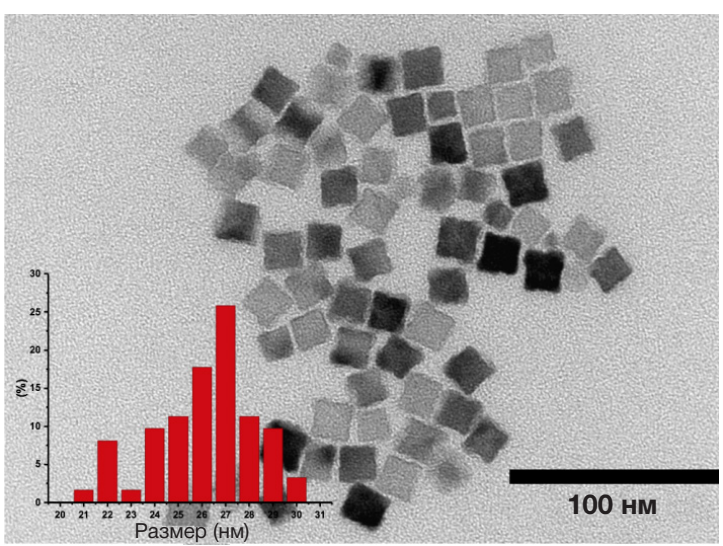

Рис. 1. ПЭМ-изображение и гистограмма распределения по размерам образцов наночастиц магнетита: с размером в диапазоне от 10 до 20 нм (A); с размером в диапазоне от 20 до 30 нм (Б) 
Крупные НЧ кубической формы (CbB) имеют Ms, равную $89 \mathrm{~A} \cdot \mathrm{M}^{2} /$ Кг. Намагниченность насьщения была нормирована на количество фазы оксида железа за вычетом массы органических стабилизаторов, определенной с помощью ТГ/ДСК-анализа (рис. 2В).

На ТГ-кривой для образца CbS отмечаются три участка с резкой потерей массы: первый - в области $150-300{ }^{\circ} \mathrm{C}$ которая соответствует десорбции органических соединений, нековалентно связанных с поверхностью НЧ; второй находится в области $300-450{ }^{\circ} \mathrm{C}$, где десорбируются стабилизаторы, связанные ковалентно, а в области 600-700 ${ }^{\circ} \mathrm{C}$ (это третий участок) происходит фазовое превращение магнетита. Для ТГ-кривой образца CbB участок десорбции ковалентно и нековалентно связанных органических молекул с поверхности более гладкий; при температуре выше $500{ }^{\circ} \mathrm{C}$ также наблюдается фазовый переход.

Н4 кубической формы, имеющие на поверхности гидрофобные остатки олеиновой кислоты, могут быть диспергированы в неполярных органических растворителях (хлорофоорм, гексан); они представляют собой седиментационно-устойчивую коллоидную систему. Средний гидродинамический размер образцов CbS и CbB в хлороформе представлен на рис. 3 А. Коэфффициент полидисперсности (Pdl) составляет 0,113 и 0,151 для Н4 со средним фактическим размером 16 нм и 27 нм соответственно. Для перевода в водную фазу НЧ магнетита были покрыты формуляцией липидов, состоящей из липидоида C12-200, холестерина, DSPC и 1,2- DMG-mPEG в массовом соотношении $75: 15: 7: 3$. После покрытия образцов формуляцией липидов и перевода в водную фазу средний гидродинамический размер образца CbS стал равен 50,9 нм (Pdl = 0,119) (рис. 3Б), поэтому, основываясь на характере распределения, можно предположить, что большая часть ЛНЧ находится в растворе в виде одиночных частиц, а меньшая - собирается в нанокластеры по несколько частиц. У образца $\mathrm{CbB}$ - противоположный характер распределения: средний гидродинамический размер, равный 118,6 нм (Pdl = 0,201) (рис. 3Б) более чем в 4 раза превосходит фактический, что говорит о большей кластеризации НЧ кубической формы после покрытия

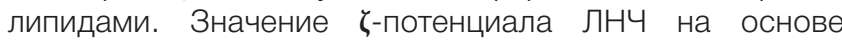
кубических НЧ магнетита в воде является положительным и составляет +20,5 мВ и +34,3 мB для образцов CbB и CbS соответственно.

Выживаемость клеток после инкубации с образцами CbS и CbB для клеточных линий HepG2 и Huh7 представлена на рис. 4. На основе MTS-теста была определена $I_{50}$ образца $\mathrm{CbB}$, которая составила 21,5 мкг/мл по магнетиту для культуры клеток НерG2 и 126 мкг/мл (в 6 раз выше) по магнетиту для Huh7. Образец CbS не продемонстрировал цитотоксичность в исследуемых концентрациях ни для одной из протестированных культур клеток.

На рис. 5 А представлены репрезентативные Т2взвешенные коронарные срезы, на которых хорошо заметно накопление НЧ в печени и селезенке лабораторных мышей через 0-48 ч после внутривенного введения. Уже спустя 1 ч после инъекции в этих органах наблюдали выраженное накопление $\mathrm{CbS}$ и $\mathrm{CbB}$, которое сохранялось неизменным в последующие 48 ч. Полученные результаты свидетельствуют о том, что при внутривенном введении HЧ эффективно накапливаются в указанных органах. Следует отметить, что МРТ является полуколичественным методом и не позволяет сделать однозначных выводов о
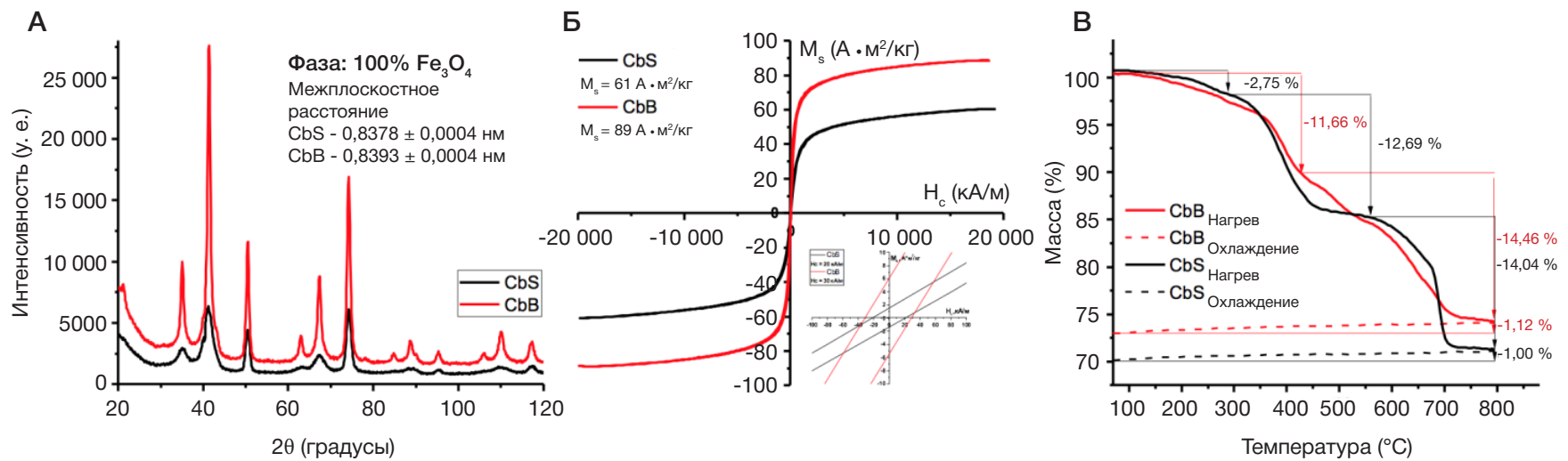

Рис. 2. Физико-химические свойства НЧ кубической формы: по результатам рентгенофазового анализа (А); петли магнитного гистерезиса (Б); по результатам ТГ/ДСК-анализа (B)

A

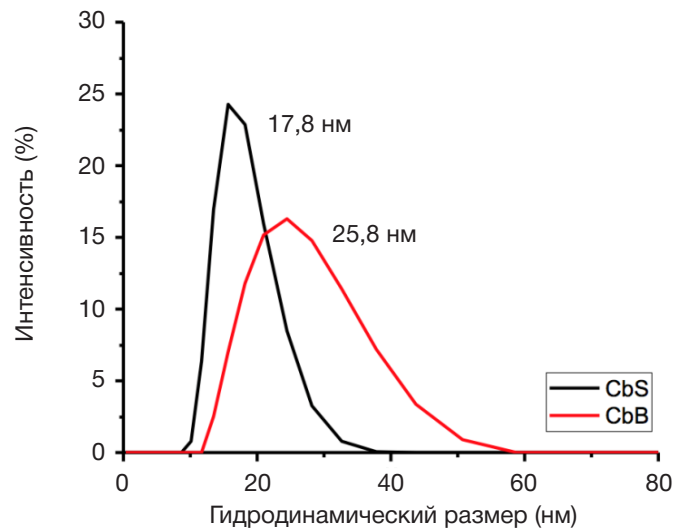

Б

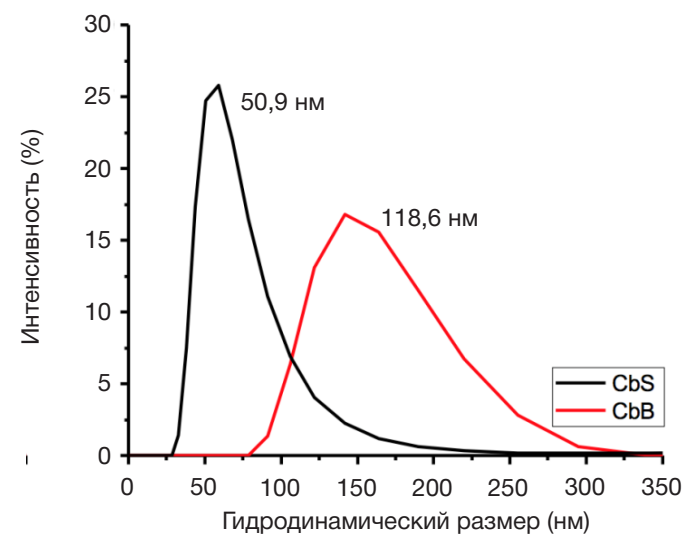

Рис. 3. А. Гидродинамический размер НЧ кубической формы в хлороформе до покрытия липидами. Б. Гидродинамический размер нанокластеров в воде после покрытия липидами 
различиях в накоплении препарата между разными типами НЧ, а также между различными органами. В связи с этим проводили дополнительное исследование накопления железа во внутренних органах методом АЭС (рис. 5Б). Больше всего ЛНЧ секвестрируется в печени и селезенке, что соответствует результатам МРТ-исследования (рис. 5А). Накопление исследуемых ЛНЧ в других внутренних органах пренебрежимо мало. Кроме того, можно заключить, что образец CbS наиболее эффективно накапливается в печени (84\% от введенных ЛНЧ), тогда как образец СbВ, напротив, характеризуется относительно низким в ней накоплением (43\% от введенной дозы).

На снимках срезов печени, окрашенных по методу Перлса, в каждой из исследуемых групп хорошо видно повышенное накопление железа в печени для обоих типов НЧ по сравнению с контрольным образцом (рис. 6). Кроме того, обращает на себя внимание различие в характере накопления железа между исследуемыми образцами. Образец CbS демонстрирует диффузное накопление в паренхиме органа - предположительно, в гепатоцитах. Для образца CbB наблюдается смешанный паттерн окраски: частично накопление происходит в клетках неправильной формы, расположенных на границе синусоидов и паренхимы - предположительно, в макрофагах, а частично отмечается диффузное окрашивание, характерное для накопления в гепатоцитах.

\section{ОБСУЖДЕНИЕ РЕЗУЛЬТАТОВ}

В классическом механизме роста НЧ можно выделить три этапа: на первом этапе прекурсор - олеат железа (III) разлагается с образованием нестабильных железо-

A

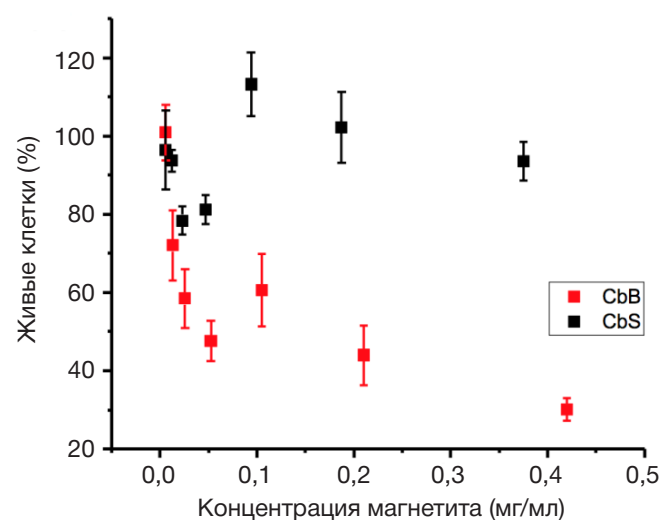

органических интермедиатов вплоть до достижения критической концентрации пересыщения, необходимой для зародышеобразования. На втором этапе концентрация интермедиатов в среде уменьшается - вследствие присоединения их молекул к поверхности зародышей, которые начинают таким образом постепенно расти. На последнем этапе концентрация интермедиата падает до термодинамически стабильных значений, а образованные Н4 претерпевают изменения путем созревания по Оствальду. Достижение роста НЧ с постоянной скоростью за счет непрерывного контролируемого добавления прекурсора на втором этапе приводит к равномерному увеличению размера с сохранением монодисперсности. Такой подход позволяет получить НЧ с точно заданным, теоретически сколь угодно большим размером и низкой полидисперсностью, что особенно актуально для частиц размером больше 20 нм. Дополнительное введение в реакционную среду стабилизатора - олеата натрия, который специсически адсорбируется на плоскости (111), приводит к образованию НЧ кубической формы (рис. 1Б). Скорость, концентрация и длительность введения прекурсора на второй стадии синтеза образца СbB подбирались экспериментально. При низкой скорости подачи раствора олеата железа (III) НЧ претерпевали изменение размера путем оствальдовского созревания происходил перенос вещества от мелких частиц к крупным, следствием чего явилось увеличение полидисперсности. Введение прекурсора на большей скорости резко повышало концентрацию интермедиатов в среде, что приводило к реализации механизма первичного зародышеобразования и, соответственно, росту полидисперсности НЧ.

Б

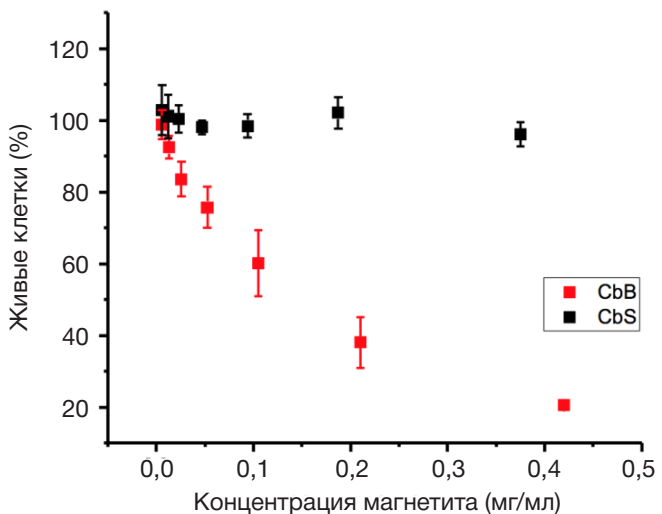

Рис. 4. Оценка цитотоксичности различных концентраций липидоподобных нанокластеров с магнитным ядром CbS и CbB на клеточных линиях НерG2 (A); Huh7 (Б)

A
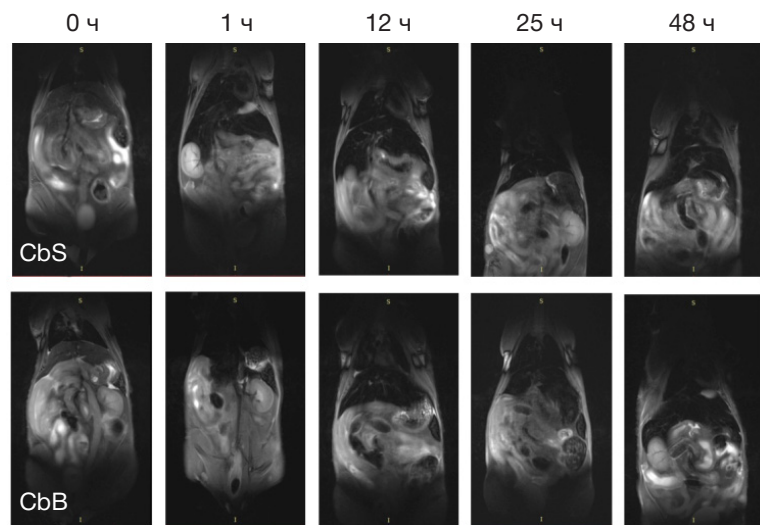

Б

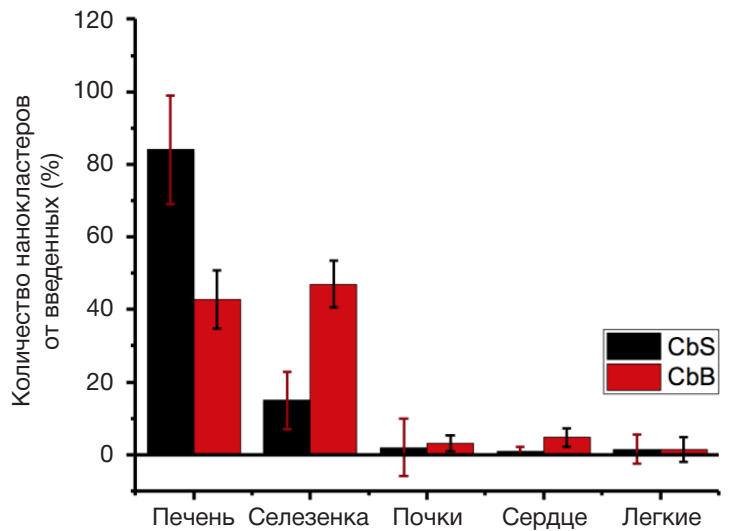

Рис. 5. Исследование локализации нанокластеров с магнитным ядром CbS и CbB в печени и селезенке методом MPT (A); во всех исследованных органах методом АЭС (Б) 

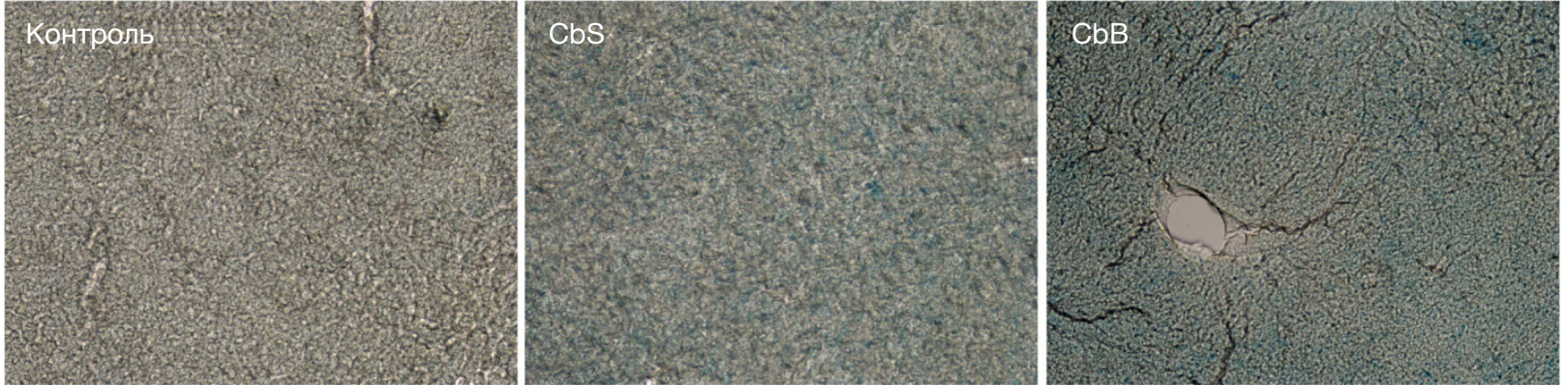

Рис. 6. Исследование локализации нанокластеров с магнитным ядром CbS и CbB в печени на клеточном уровне (окраска по Перлсу)

Результаты рентгенофазового анализа обоих образцов хорошо согласуются с литературными данными [28].

Намагниченность насыщения (Ms) для образца CbS согласуется с указанным в литературе значением для Н4 магнетита со средним размером, сопоставимым с размером образца $\mathrm{CbS}[23,29]$. Значение Ms крупных HЧ кубической формы (CbB) очень высокое, оно соизмеримо с намагниченностью насыщения массивного образца [30] или очень крупных НЧ [31].

Согласно данным ТГ/ДСК-анализа (рис. 2В), количество органической фазы, адсорбированной на поверхности НЧ оксида железа, составляет 15,5\% от общей массы для образца $\mathrm{CbS}$ и 11,7\% для образца CbB. При одинаковой массе образцов с уменьшением среднего размера НЧ увеличивается отношение площади поверхности к объему и, соответственно, растет число молекул стабилизаторов, которые могут там адсорбироваться. Эта закономерность существенно влияет на стабильность коллоидной системы, которая в большой степени обусловливается двумя факторами: стерической стабилизацией за счет наличия длинных гидрофобных остатков у олеиновой кислоты, адсорбированной на поверхности НЧ, и их агрегацией вследствие взаимного магнитного взаимодействия. С увеличением размера магнитного ядра образец CbB демонстрирует более высокий показатель Pdl (ФКС), наблюдается расширение пика гидродинамического размера по сравнению с образцом CbS, что подтверждает бо̀льшую кластеризацию образца за счет увеличения размера магнитного ядра, обусловленную вкладом более выраженного магнитного взаимодействия.

Гидродинамический размер НЧ и физико-химические свойства их поверхности в значительной мере определяют характер клеточных взаимодействий, эндоцитарную маршрутизацию и эффективность поглощения [32, 33]. Для НЧ внутриклеточная локализация связана с дезорганизацией цитоскелета [34, 35]. Наночастицы при значительном уровне накопления индуцировали десормации сети актина и тубулина в нейронных клеткахпредшественницах мыши и первичных эндотелиальных клетках кровеносных сосудов человека [36]. Нами было высказано предположение, что простое физическое присутствие большого количества НЧ, заключенных в громоздкие лизосомальные структуры, обычно расположенные в околоядерной области, стерически затрудняет функцию цитоскелета и тем самым вызывает ремоделирование сети актина. Результаты исследования на определение цитотоксичности ЛНЧ хорошо коррелируют с теорией о токсичности НЧ вследствие дезорганизации цитоскелета, поскольку образец $\mathrm{CbB}$, фактический размер которого в 1,7 раза превышает размер образца CbS, оказался токсичным для клеточных культур в исследуемых концентрациях - в отличие от образца CbS, исследуемого при аналогичном фазовом составе, составе покрытия и морфологии.

Исходные характеристики магнитных НЧ, такие как однородность по размеру и форме, высокая агрегационная устойчивость и стабильность покрытия, являются ключевыми факторами в понимании процессов фармакокинетики и биораспределения. Хорошо известно, что НЧ с гидродинамическим размером менее 20-30 нм фильтруются почечными клубочками, а с размером более 200 нм в большей степени накапливаются в селезенке [37]. Н4 в диапазоне размеров от 30 до 200 нм обычно секвестрируются в печени - они легко поглощаются эндоцитозными везикулами (со средним диаметром 40-60 нм), впрочем, частицы крупнее 150 нм фагоцитируются макрофагами (верхний предел для прохождения через кавеолу). Поэтому идеальный гидродинамический размер ЛНЧ для доставки в печень составляет от 30 до 150 нм. Согласно результатам проведенных нами гистологического исследования и изучения биораспределения НЧ в органах, образец СbB в основном захватывается клетками моноцитарно-макрофагальной системы организма, что объясняет равномерное распределение НЧ между печенью и селезенкой. Это согласуется с предыдущими исследованиями [38]. И, напротив, образец CbS не секвестрируется в макрофагах, а доставляется в гепатоциты, что определяет его преимущественное накопление в печени и согласуется с литературными данными для НЧ с магнитным ядром сопоставимого размера [39]. Вероятно, НЧ кубической формы более крупного размера (CbB) при введении в кровоток мыши увеличиваются в размере из-за адсорбции на их поверхности сывороточных белков, которые образуют «корону» биологических макромолекул [40], ввиду чего увеличивается гидродинамический размер этих НЧ и накопление происходит в большей степени в селезенке.

\section{ВЫВОДЫ}

Исследованная система адресной доставки антисмысловых препаратов в клетки печени показала свою перспективность как in vivo, так и in vitro. У полученных ЛНЧ CbS выявлена низкая токсичность по отношению к клеточным линиям Huh7 и HерG2. Изучение биологического распределения ЛНч с магнитными ядрами различных размеров in vivo показало значительный уровень накопления в печени, который наблюдался уже через 1 ч после инъекции и поддерживался в течение 48 ч (МРТ). Кубические НЧ с магнитным ядром оксида железа в диапазоне размеров от 10 до 20 нм и гидродинамическим размером менее 100 нм достигли более высоких уровней накопления в гепатоцитах (свыше 80\% от введенной дозы), тогда как более крупные НЧ аккумулировались в клетках Купфера и других компонентах ретикулоэндотелиальной системы. 


\section{Литература}

1. Wouters $K$, Shiri-Sverdlov R, van Gorp PJ, van Bilsen M, Hofker MH. Understanding hyperlipidemia and atherosclerosis: lessons from genetically modified apoe and Idlr mice. Clin Chem Lab Med [Internet]. 2005 [cited 2017 Oct 28]; 43 (5): 470-9. Available from: http://www.ncbi.nlm.nih.gov/pubmed/15899668.

2. Pagidipati NJ, Gaziano TA. Estimating Deaths From Cardiovascular Disease: A Review of Global Methodologies of Mortality Measurement. Circulation. 2013; 127 (6): 749-56.

3. Sullenger BA, Nair S. From the RNA world to the clinic. Science 17. 2016; 352 (6292): 1417-20.

4. McClorey G, Wood MJ. An overview of the clinical application of antisense oligonucleotides for RNA-targeting therapies. Curr Opin Pharmacol. 2015; (24): 52-8.

5. Kulkarni JA, Cullis PR, van der Meel R. Lipid Nanoparticles Enabling Gene Therapies: From Concepts to Clinical Utility. Nucleic Acid Ther. 2018; 28 (3): 146-57.

6. Mahajan UM, Teller S, Sendler M, Palankar R, van den Brandt C, Schwaiger $T$ et al. Tumour-specific delivery of siRNA-coupled superparamagnetic iron oxide nanoparticles, targeted against PLK1, stops progression of pancreatic cancer. Gut. 2016; 65 (11): 1838-49.

7. Kim M-C, Lin MM, Sohn Y, Kim J-J, Kang BS, Kim DK. Polyethyleneimine-associated polycaprolactone-Superparamagnetic iron oxide nanoparticles as a gene delivery vector. J Biomed Mater Res Part B Appl Biomater. 2017; 105 (1): 145-54.

8. Nayerossadat N, Ali P, Maedeh T. Viral and nonviral delivery systems for gene delivery. Adv Biomed Res. 2012; 1 (1): 27.

9. Yang N. An overview of viral and nonviral delivery systems for microRNA. Int J Pharm Investig. 2015; 5 (4): 179.

10. Nayak S, Herzog RW. Progress and prospects: immune responses to viral vectors. Gene Ther. 2010; 17 (3): 295-304.

11. Qiu J, Kong L, Cao X, Li A, Wei P, Wang L et al. Enhanced Delivery of Therapeutic siRNA into Glioblastoma Cells Using DendrimerEntrapped Gold Nanoparticles Conjugated with $\beta$-Cyclodextrin. Nanomaterials. 2018; 8 (3): 131.

12. Singh $\mathrm{Y}$, Tomar S, Khan S, Meher JG, Pawar VK, Raval $\mathrm{K}$ et al. Bridging small interfering RNA with giant therapeutic outcomes using nanometric liposomes. J Control Release. 2015; (220): 368-87.

13. Leung AK, Tam YY, Cullis PR. Lipid Nanoparticles for Short Interfering RNA Delivery. Adv Genet. 2014; (88): 71-110.

14. Nakamura $T$, Yamada $K$, Fujiwara $Y$, Sato $Y$, Harashima $H$. Reducing the Cytotoxicity of Lipid Nanoparticles Associated with a Fusogenic Cationic Lipid in a Natural Killer Cell Line by Introducing a Polycation-Based siRNA Core. Mol Pharm. 2018; 15 (6): 2142-50.

15. Jin M, Jin G, Kang L, Chen L, Gao Z, Huang W. Smart polymeric nanoparticles with $\mathrm{pH}$-responsive and PEG-detachable properties for co-delivering paclitaxel and survivin siRNA to enhance antitumor outcomes. Int J Nanomedicine. 2018; (13): 2405.

16. Novobrantseva TI, Borodovsky A, Wong J, Klebanov B, Zafari M, Yucius $\mathrm{K}$ et al. Systemic RNAi-mediated Gene Silencing in Nonhuman Primate and Rodent Myeloid Cells. Mol Ther Nucleic Acids. 2012; (1): e4.

17. Kumar V, Qin J, Jiang Y, Duncan RG, Brigham B, Fishman S et al. Shielding of Lipid Nanoparticles for siRNA Delivery: Impact on Physicochemical Properties, Cytokine Induction, and Efficacy. Mol Ther Nucleic Acids. 2014; (3): e210.

18. Alshehri A, Grabowska A, Stolnik S. Pathways of cellular internalisation of liposomes delivered siRNA and effects on siRNA engagement with target mRNA and silencing in cancer cells. Sci Rep. 2018; 8 (1): 3748.

19. Soenen SJ, Hodenius M, De Cuyper M. Magnetoliposomes: versatile innovative nanocolloids for use in biotechnology and biomedicine. Nanomedicine. 2009; 4 (2): 177-91.

20. Dobson J. Magnetic nanoparticles for drug delivery. Drug Dev Res [Internet]. 2006 [cited 2017 Sep 18]; 67(1): 55-60. Available from: http://onlinelibrary. wiley.com/doi/10.1002/ddr.20067/abstract.

21. Zhang JQ, Zhang ZR, Yang H, Tan QY, Qin SR, Qiu XL. Lyophilized paclitaxel magnetoliposomes as a potential drug delivery system for breast carcinoma via parenteral administration: in vitro and in vivo studies. Pharm Res [Internet]. 2005 [cited 2017 Sep 18]; 22 (4): 573-83. Available from: http://www.ncbi.nlm.nih.gov/ pubmed/15846465.

22. Yang L, Wang Z, Ma L, Li A, Xin J, Wei R et al. The Roles of Morphology on the Relaxation Rates of Magnetic Nanoparticles. ACS Nano. 2018; 12 (5): 4605-14.

23. Bronstein LM, Huang X, Retrum J, Schmucker A, Pink M, Stein BD et al. Influence of Iron Oleate Complex Structure on Iron Oxide Nanoparticle Formation. 2007 [cited 2017 Dec 16]; 19 (15): 3624-32. Available from: http://pubs.acs.org/doi/abs/10.1021/ cm062948j.

24. Hai HT, Yang HT, Kura H, Hasegawa D, Ogata Y, Takahashi M et al. Size control and characterization of wustite (core)/spinel (shell) nanocubes obtained by decomposition of iron oleate complex. J Colloid Interface Sci [Internet]. 2010; 346 (1): 37-42. Available from: http://dx.doi.org/10.1016/j.jcis.2010.02.025.

25. Jiang S, Eltoukhy A, Love K, Langer R, Anderson D. LipidoidCoated Iron Oxide Nanoparticles for Efficient DNA and siRNA delivery. Nano Lett [Internet]. 2013; 1-6. Available from: citeulike-article-id:12014954\%5Cnhttp://dx.doi.org/10.1021/ nl304287a.

26. Love KT, Mahon KP, Levins CG, Whitehead KA, Querbes W, Dorkin JR et al. Lipid-like materials for low-dose, in vivo gene silencing. Proc Natl Acad Sci. 2010; 107 (5): 1864-9.

27. Mosmann T. Rapid colorimetric assay for cellular growth and survival: Application to proliferation and cytotoxicity assays. J Immunol Methods. 1983; 65 (1-2): 55-63.

28. Mamani JB, Costa-Filho AJ, Cornejo DR, Vieira ED, Gamarra LF. Synthesis and characterization of magnetite nanoparticles coated with lauric acid. Mater Charact. 2013; (81): 28-36.

29. Nemati Z, Das R, Alonso J, Clements E, Phan MH, Srikanth H. Iron Oxide Nanospheres and Nanocubes for Magnetic Hyperthermia Therapy: A Comparative Study. J Electron Mater [Internet]. 2017 [cited 2017 Dec 16]; 46 (6): 3764-9. Available from: http://link. springer.com/10.1007/s11664-017-5347-6.

30. Cullity BD, Graham CD. Introduction to magnetic materials. 2nd ed. Hoboken, NJ: IEEE/Wiley, 2009; 544 p.

31. Marciello M, Connord V, Veintemillas-Verdaguer S, Vergés MA, Carrey $\mathrm{J}$, Respaud $\mathrm{M}$, et al. Large scale production of biocompatible magnetite nanocrystals with high saturation magnetization values through green aqueous synthesis. J Mater Chem B. 2013; 1 (43): 5995-6004.

32. Verma A, Stellacci F. Effect of Surface Properties on NanoparticleCell Interactions. Small. 2010; 6 (1): 12-21.

33. Adler AF, Leong KW. Emerging links between surface nanotechnology and endocytosis: Impact on nonviral gene delivery. Nano Today. 2010; 5 (6): 553-69.

34. Gupta AK, Gupta M. Cytotoxicity suppression and cellular uptake enhancement of surface modified magnetic nanoparticles. Biomaterials [Internet]. 2005 [cited 2017 Jun 9]; 26 (13): 1565-73. Available from: http://www.ncbi.nlm.nih.gov/pubmed/15522758.

35. Gupta AK, Curtis AS. Lactoferrin and ceruloplasmin derivatized superparamagnetic iron oxide nanoparticles for targeting cell surface receptors. Biomaterials. 2004; 25 (15): 3029-40.

36. Soenen SJH, Nuytten N, De Meyer SF, De Smedt SC, De Cuyper M. High Intracellular Iron Oxide Nanoparticle Concentrations Affect Cellular Cytoskeleton and Focal Adhesion Kinase-Mediated Signaling. Small. 2010; 6 (7): 832-42.

37. Berry CC. Progress in functionalization of magnetic nanoparticles for applications in biomedicine. J Phys D Appl Phys. 2009; 42 (22): 224003.

38. Zhang J, Ring HL, Hurley KR, Shao Q, Carlson CS, Idiyatullin D et al. Quantification and biodistribution of iron oxide nanoparticles in the primary clearance organs of mice using T1 contrast for heating. Magn Reson Med [Internet]. 2017 [cited 2017 Dec 22]; 78 (2): 702-12. Available from: http://www.ncbi.nlm.nih.gov/ pubmed/27667655.

39. Bargheer D, Giemsa A, Freund B, Heine M, Waurisch C, Stachowski GM et al. The distribution and degradation of radiolabeled superparamagnetic iron oxide nanoparticles and quantum dots in mice. Beilstein J Nanotechnol. 2015; (6): 111-23. 
40. Ruiz A, Hernández Y, Cabal C, González E, Veintemillas-Verdaguer S, Martínez E, et al. Biodistribution and pharmacokinetics of uniform magnetite nanoparticles chemically modified with polyethylene glycol. Nanoscale. 2013; 5 (23): 11400-8.

\section{References}

1. Wouters K, Shiri-Sverdlov R, van Gorp PJ, van Bilsen M, Hofker MH Understanding hyperlipidemia and atherosclerosis: lessons from genetically modified apoe and Idlr mice. Clin Chem Lab Med [Internet]. 2005 [cited 2017 Oct 28]; 43 (5): 470-9. Available from: http://www.ncbi.nlm.nih.gov/pubmed/15899668.

2. Pagidipati NJ, Gaziano TA. Estimating Deaths From Cardiovascular Disease: A Review of Global Methodologies of Mortality Measurement. Circulation. 2013; 127 (6): 749-56.

3. Sullenger BA, Nair S. From the RNA world to the clinic. Science 17. 2016; 352 (6292): 1417-20.

4. McClorey G, Wood MJ. An overview of the clinical application of antisense oligonucleotides for RNA-targeting therapies. Curr Opin Pharmacol. 2015; (24): 52-8.

5. Kulkarni JA, Cullis PR, van der Meel R. Lipid Nanoparticles Enabling Gene Therapies: From Concepts to Clinical Utility. Nucleic Acid Ther. 2018; 28 (3): 146-57.

6. Mahajan UM, Teller S, Sendler M, Palankar R, van den Brandt C, Schwaiger $T$ et al. Tumour-specific delivery of siRNA-coupled superparamagnetic iron oxide nanoparticles, targeted against PLK1, stops progression of pancreatic cancer. Gut. 2016; 65 (11): 1838-49.

7. Kim M-C, Lin MM, Sohn Y, Kim J-J, Kang BS, Kim DK Polyethyleneimine-associated polycaprolactone-Superparamagnetic iron oxide nanoparticles as a gene delivery vector. J Biomed Mater Res Part B Appl Biomater. 2017; 105 (1): 145-54.

8. Nayerossadat N, Ali P, Maedeh T. Viral and nonviral delivery systems for gene delivery. Adv Biomed Res. 2012; 1 (1): 27.

9. Yang N. An overview of viral and nonviral delivery systems for microRNA. Int J Pharm Investig. 2015; 5 (4): 179.

10. Nayak S, Herzog RW. Progress and prospects: immune responses to viral vectors. Gene Ther. 2010; 17 (3): 295-304.

11. Qiu J, Kong L, Cao X, Li A, Wei P, Wang L et al. Enhanced Delivery of Therapeutic siRNA into Glioblastoma Cells Using DendrimerEntrapped Gold Nanoparticles Conjugated with $\beta$-Cyclodextrin Nanomaterials. 2018; 8 (3): 131

12. Singh $Y$, Tomar S, Khan S, Meher JG, Pawar VK, Raval K et al. Bridging small interfering RNA with giant therapeutic outcomes using nanometric liposomes. J Control Release. 2015; (220): 368-87.

13. Leung AK, Tam YY, Cullis PR. Lipid Nanoparticles for Short Interfering RNA Delivery. Adv Genet. 2014; (88): 71-110.

14. Nakamura T, Yamada K, Fujiwara $Y$, Sato $Y$, Harashima $H$. Reducing the Cytotoxicity of Lipid Nanoparticles Associated with a Fusogenic Cationic Lipid in a Natural Killer Cell Line by Introducing a Polycation-Based siRNA Core. Mol Pharm. 2018, 15 (6): 2142-50.

15. Jin M, Jin G, Kang L, Chen L, Gao Z, Huang W. Smart polymeric nanoparticles with $\mathrm{pH}$-responsive and PEG-detachable properties for co-delivering paclitaxel and survivin siRNA to enhance antitumor outcomes. Int J Nanomedicine. 2018; (13): 2405.

16. Novobrantseva TI, Borodovsky A, Wong J, Klebanov B, Zafari M, Yucius $\mathrm{K}$ et al. Systemic RNAi-mediated Gene Silencing in Nonhuman Primate and Rodent Myeloid Cells. Mol Ther Nucleic Acids. 2012; (1): e4

17. Kumar V, Qin J, Jiang Y, Duncan RG, Brigham B, Fishman S et al. Shielding of Lipid Nanoparticles for siRNA Delivery: Impact on Physicochemical Properties, Cytokine Induction, and Efficacy. Mol Ther Nucleic Acids. 2014; (3): e210.

18. Alshehri A, Grabowska A, Stolnik S. Pathways of cellular internalisation of liposomes delivered siRNA and effects on SiRNA engagement with target mRNA and silencing in cancer cells. Sci Rep. 2018; 8 (1): 3748

19. Soenen SJ, Hodenius M, De Cuyper M. Magnetoliposomes: versatile innovative nanocolloids for use in biotechnology and biomedicine. Nanomedicine. 2009; 4 (2): 177-91.

20. Dobson J. Magnetic nanoparticles for drug delivery. Drug Dev Res

[Internet]. 2006 [cited 2017 Sep 18]; 67(1): 55-60. Available from: http://onlinelibrary.wiley.com/doi/10.1002/ddr.20067/abstract.

21. Zhang JQ, Zhang ZR, Yang H, Tan QY, Qin SR, Qiu XL. Lyophilized paclitaxel magnetoliposomes as a potential drug delivery system for breast carcinoma via parenteral administration: in vitro and in vivo studies. Pharm Res [Internet]. 2005 [cited 2017 Sep 18]; 22 (4): 573-83. Available from: http://www.ncbi.nlm.nih.gov/ pubmed/15846465.

22. Yang L, Wang Z, Ma L, Li A, Xin J, Wei R et al. The Roles of Morphology on the Relaxation Rates of Magnetic Nanoparticles. ACS Nano. 2018; 12 (5): 4605-14.

23. Bronstein LM, Huang $X$, Retrum J, Schmucker A, Pink M, Stein BD et al. Influence of Iron Oleate Complex Structure on Iron Oxide Nanoparticle Formation. 2007 [cited 2017 Dec 16]; 19 (15): 3624-32. Available from: http://pubs.acs.org/doi/abs/10.1021/ cm062948j.

24. Hai HT, Yang HT, Kura H, Hasegawa D, Ogata Y, Takahashi M et al. Size control and characterization of wustite (core)/spinel (shell) nanocubes obtained by decomposition of iron oleate complex. J Colloid Interface Sci [Internet]. 2010; 346 (1): 37-42. Available from: http://dx.doi.org/10.1016/j.jcis.2010.02.025.

25. Jiang S, Eltoukhy A, Love K, Langer R, Anderson D. LipidoidCoated Iron Oxide Nanoparticles for Efficient DNA and siRNA delivery. Nano Lett [Internet]. 2013; 1-6. Available from: citeulikearticle-id:12014954\%5Cnhttp://dx.doi.org/10.1021/nl304287a.

26. Love KT, Mahon KP, Levins CG, Whitehead KA, Querbes W, Dorkin JR et al. Lipid-like materials for low-dose, in vivo gene silencing. Proc Natl Acad Sci. 2010; 107 (5): 1864-9.

27. Mosmann T. Rapid colorimetric assay for cellular growth and survival: Application to proliferation and cytotoxicity assays. J Immunol Methods. 1983; 65 (1-2): 55-63.

28. Mamani JB, Costa-Filho AJ, Cornejo DR, Vieira ED, Gamarra LF. Synthesis and characterization of magnetite nanoparticles coated with lauric acid. Mater Charact. 2013; (81): 28-36.

29. Nemati Z, Das R, Alonso J, Clements E, Phan MH, Srikanth H. Iron Oxide Nanospheres and Nanocubes for Magnetic Hyperthermia Therapy: A Comparative Study. J Electron Mater [Internet]. 2017 [cited 2017 Dec 16]; 46 (6): 3764-9. Available from: http://link. springer.com/10.1007/s11664-017-5347-6.

30. Cullity BD, Graham CD. Introduction to magnetic materials. 2nd ed. Hoboken, NJ: IEEE/Wiley, 2009; 544 p.

31. Marciello M, Connord V, Veintemillas-Verdaguer S, Vergés MA Carrey J, Respaud M, et al. Large scale production of biocompatible magnetite nanocrystals with high saturation magnetization values through green aqueous synthesis. J Mater Chem B. 2013; 1 (43): 5995-6004.

32. Verma A, Stellacci F. Effect of Surface Properties on NanoparticleCell Interactions. Small. 2010; 6 (1): 12-21.

33. Adler AF, Leong KW. Emerging links between surface nanotechnology and endocytosis: Impact on nonviral gene delivery. Nano Today. 2010; 5 (6): 553-69.

34. Gupta AK, Gupta M. Cytotoxicity suppression and cellular uptake enhancement of surface modified magnetic nanoparticles. Biomaterials [Internet]. 2005 [cited 2017 Jun 9]; 26 (13): 1565-73. Available from: http://www.ncbi.nlm.nih.gov/pubmed/15522758.

35. Gupta AK, Curtis AS. Lactoferrin and ceruloplasmin derivatized superparamagnetic iron oxide nanoparticles for targeting cell surface receptors. Biomaterials. 2004; 25 (15): 3029-40.

36. Soenen SJH, Nuytten N, De Meyer SF, De Smedt SC, De Cuyper M. High Intracellular Iron Oxide Nanoparticle Concentrations Affect Cellular Cytoskeleton and Focal Adhesion Kinase-Mediated Signaling. Small. 2010; 6 (7): 832-42.

37. Berry CC. Progress in functionalization of magnetic nanoparticles for applications in biomedicine. J Phys D Appl Phys. 2009; 42 (22): 224003. 


\section{ORIGINAL RESEARCH I NANOMEDICINE}

38. Zhang J, Ring HL, Hurley KR, Shao Q, Carlson CS, Idiyatullin D et al. Quantification and biodistribution of iron oxide nanoparticles in the primary clearance organs of mice using T1 contrast for heating. Magn Reson Med [Internet]. 2017 [cited 2017 Dec 22]; 78 (2): 702-12. Available from: http://www.ncbi.nlm.nih.gov/ pubmed/27667655

39. Bargheer D, Giemsa A, Freund B, Heine M, Waurisch C,
Stachowski GM et al. The distribution and degradation of radiolabeled superparamagnetic iron oxide nanoparticles and quantum dots in mice. Beilstein J Nanotechnol. 2015; (6): 111-23.

40. Ruiz A, Hernández Y, Cabal C, González E, Veintemillas-Verdaguer S, Martínez E, et al. Biodistribution and pharmacokinetics of uniform magnetite nanoparticles chemically modified with polyethylene glycol. Nanoscale. 2013; 5 (23): 11400-8. 